\title{
Shielding Verifications for a Gamma Irradiation Facility Considering the Installation of a New Automatic Product Loading System
}

\author{
Maritza Rodriguez Gual, Amir Zacarias Mesquita, \\ Edson Ribeiro, and Pablo Andrade Grossi
}

Nuclear Technology Development Centre (CDTN), Brazilian Nuclear Energy Commission (CNEN), Campus of UFMG, Pampulha, Belo Horizonte, MG, Brazil

Correspondence should be addressed to Amir Zacarias Mesquita; amir@cdtn.br

Received 1 June 2017; Revised 28 August 2017; Accepted 11 September 2017; Published 25 October 2017

Academic Editor: Michael I. Ojovan

Copyright (C) 2017 Maritza Rodriguez Gual et al. This is an open access article distributed under the Creative Commons Attribution License, which permits unrestricted use, distribution, and reproduction in any medium, provided the original work is properly cited.

A new system has been designed to automatically load the samples to be irradiated at the gamma irradiation facility of the Nuclear Technology Development Centre (CDTN) at Belo Horizonte, Brazil. The objective of this system is the optimization of the experiments performed at the Gamma Irradiation Laboratory for short-time irradiations without interruption of the irradiator cycles. The installation of this new system requires the opening of a hole at the labyrinth door to allow the loading of irradiating products. Due to this alteration on the original design, the door opening into the labyrinth requires shielding verification. The dose rate with the door open is calculated using Monte Carlo MCNPX v 2.6.0 code. The Monte Carlo source simulations were validated with experimental measurements of dose rate. The simulation demonstrated that a hole can be opened at the labyrinth entrance when installing an automatic loading system. Not only does it comply with dose constraint requirements, but it also complies with national and international standards.

\section{Introduction}

Gamma Irradiation Laboratory installed at the Nuclear Technology Development Centre (CDTN), Belo Horizonte, Brazil, has shown a wide range of applications. To date, this irradiator has been used for a number of applications like inactivation of pathogenic microbes in infected blood products, preventing graft-versus-host disease (GVHD) in immune suppressed patients [1], enhancement or alteration of molecular structure and other properties of polymers [2], altering gemstone color [3], and others [4-7].

The high demand of the gamma irradiation facility to conduct the wide range of applications, as previously mentioned, requires innovative solutions that could bring improved gamma irradiation facility efficiency. A new automatic product loading system for the laboratory was proposed [8]. The system is required for optimizations of experiments performed for short-time irradiations without interruption of the irradiator cycles.
As a result, the idea of installation and operation of this system requires the opening of a hole at the labyrinth door to allow the loading of irradiating products without interrupting irradiator operation. One of the requirements for installation was a premise that followed from the conceptual design: the installation must not compromise personnel safety or equipment operations. Due to this alteration of the original design, we needed to know the gamma doses rates and profile that resulted from opening the door of the labyrinth.

International Commission on Radiological Protection (ICRP) recommends the cumulative dose limit of $20 \mathrm{mSv} / \mathrm{y}$ averaged over five years for occupational exposed workers and $1 \mathrm{mSv} / \mathrm{y}$ for the public [9]. These limit values are adopted by the Brazilian Nuclear Energy Commission, in the norm CNEN-NN-3.01 [8]. The GammaBeam-127 (GB-127) gamma irradiation facilities are within a radiologically controlled area (RCA) and therefore the operators are considered as occupationally exposed individuals (OEIs). The workers in controlled areas should not exceed $3 / 10$ of the occupational 
dose limits. Just $6 \mathrm{mSv}$ is $3 / 10$ of the annual dose limit $(20 \mathrm{mSv})$ for exposed workers according to Brazilian norm CNEN-NN-3.01 [10]. Then the equivalent dose limit derived for OEIs calculation would be equivalent to $0.003 \mathrm{mSv} / \mathrm{h}$ $(3 \mu \mathrm{Sv} / \mathrm{h})$.

The objective of this study is to verify, using Monte Carlo MCNPX v 2.6 .0 code [11], that when installing a new automated product loading system at the Gamma Irradiation Facility, the OEIs absorbed doses do not exceed the limits established for the regulations. The resulting value will then be compared to the investigation level (3/10 of the annual limit for IOEs). Gamma radiation doses rates and the profile are estimated at the labyrinth entrance door, taking into consideration the worst scenario, which is an operator working with the labyrinth hole open. This hole is located in the door, allowing the automatized system to load products for irradiation.

\section{Materials and Methods}

The ${ }^{60}$ Co gamma rays source of the gamma irradiation facility has maximum activity of $2.220 \mathrm{TBq}(60.000 \mathrm{Ci})$, which is composed by 12 double encapsulated radioactive pencils placed in a rack. The facility is classified by the IAEA as category II (dry storage facility) and source category based on the activity thresholds for radionuclides is classified as category 1 [12-15]. The control room of the irradiator is a controlled area; therefore, its operators are considered occupationally exposed individuals (OEIs).

The labyrinth was modelled with the Monte Carlo code MCNPX v. 2.6.0. This model includes geometric and structural details of the source of the irradiator and the labyrinth with walls, ceiling, floor, and door. The concrete of walls, floor, and ceiling was assumed to have a density of $2.453 \mathrm{~g} / \mathrm{cm}^{3}$ (being heavier than ordinary concrete) and to have the elemental compositions of ordinary concrete. The ordinary concrete composition in weight fraction was $\mathrm{H}$ (0.0221), C (0.0024), O (0.5749), Na (0.0152), Mg (0.0012), $\mathrm{Al}$ (0.0199), Si (0.3046), K (0.0100), and Ca (0.042). The composition of the concrete was taken from the International Commission on Radiation Units and Measurements [16]. The material of the labyrinth entrance door was iron with density of $7.87 \mathrm{~g} / \mathrm{cm}^{3}$ and thickness of $6 \mathrm{~mm}$.

The MCNP option utilized for this problem was the energy fluence (tally Mnemonic ${ }^{*} \mathrm{~F} 5$, in $\mathrm{MeV} / \mathrm{cm}^{2}$ ) for absorbed-dose calculation. With F6 tally in $\mathrm{MeV} / \mathrm{g}$ (energy deposition tally) the computed time required was extremely large without reaching a desired level of precision. For this reason, it was decided to use output F5 tally for accelerating calculations.

MCNP Dose energy card (DEn) and Dose function card (DFn) were used to introduce the conversion factors from energy fluence into the kerma in air. These factors are the $\left(\mu_{\mathrm{en}}(E) / \rho\right)$ tabulated in Attix [17]. For low-energy photons, kerma is numerically approximately the same as absorbed doses. Photons only deposit energy through electrons and, for low-energy photons, the secondary electrons have very short range; in other words, the energy is deposited locally.
Finally, to express the absorbed dose from $\mathrm{MeV} / \mathrm{g}$ in $\mathrm{mGy}$, the multiplication for $1.6021 \times 10^{-07}$ is used. The output from MCNP was converted to Gy/h. The equivalence that $1 \mathrm{~J} / \mathrm{kg}$ (physical unit) of gamma absorbed dose corresponds to $1 \mathrm{~Sv}$ of equivalent dose (operational quantities) is used. Dose rate was estimated at 10 points along the labyrinth. These points were located at $162.5 \mathrm{~cm}$ above the floor level and $30 \mathrm{~cm}$ from the shielding wall because these were the best positions for TLD measurements.

MCNPX was run in photon and electron mode (mode $\mathrm{PE})$ to pick up bremsstrahlung photons. The photon and electron physics are controlled with two cards (PHYS:P and PHYS:E). A detailed photon physics treatment, including photoelectric effect with fluorescence production, incoherent and coherent scattering, and pair production, has been considered in the energy range between 0.001 and $2.6 \mathrm{MeV}$ with "PHYS:P" card. For electron transport, MCNP addresses the sampling of bremsstrahlung photons at each electron substep. The "PHYS:E" card is utilized in MCNP for biasing some physical parameters such as production of secondary electrons by photons, coherent scattering, bremsstrahlung angular distribution, and production of characteristic X-rays.

In order to accelerate the calculations, the MCNP code has been parallelized in Intel's Core i7 CPU with $3.4 \mathrm{GHz}$ and $8 \mathrm{~GB}$ RAM, using the MPI multiprocessing parallel protocol, in this case with 8 processors. This way, the problem speedup is achieved. It was taking into consideration the worst situation regarding maximum dose rate: the door has the full opening hole in the labyrinth entrance with any additional shielding.

\section{Results and Discussion}

Figure 1 shows a diagram of the new automatic product loading system for the Gamma Irradiation Laboratory with the opening door of labyrinth.

The dose rate assessments were performed for 9 points of interest inside the labyrinth of the irradiator (with concrete walls of $1.9 \mathrm{~m}$ ) and 1 point at the labyrinth entrance. Figures 2 and 3 show the turntables, the cobalt 60 source, the labyrinth with walls, the ceiling, the floor, door, and the source storage container, using MCNPX, XZ, and XY views for the simulated irradiation room.

The detailed MCNPX shielding source container used for transport and storage of the GB-127 cobalt-60 source is presented in the previous work [18]. The MCNPX model of the labyrinth entrance door with and without hole is illustrated in Figure 3. Vised 22S [19] visualization tool was used to illustrate the MCNPX model.

In order to obtain a statistical error lower than $5 \%$, about $50 \times 10^{6}$ photon stories were calculated. The CPU processing time was approximately 5 days with MPI multiprocessing parallel protocol with 8 processors. In order to reduce the variance and speed up the calculations, the cell importance technique was employed. The generated cell importance rises with increasing distance from source to detector. The cell importance will be highest closer to detector. It is keeping the ratio of adjacent importance small ( 2 or less than 4 ) to avoid unnecessary creating too many particles. The cell importance 


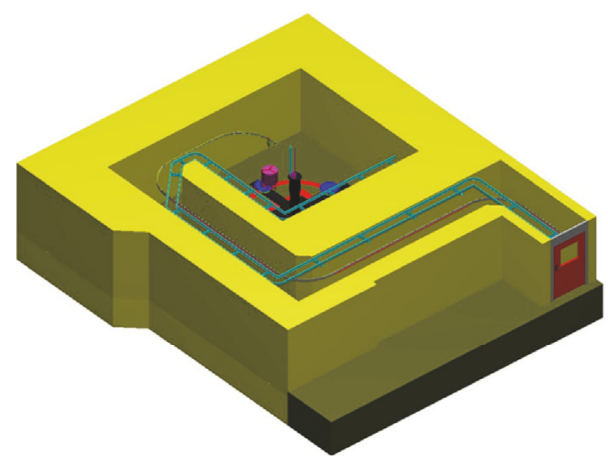

FIGURE 1: Diagram of the new automatic product loading system for the Gamma Irradiation Laboratory with the opening door of labyrinth.

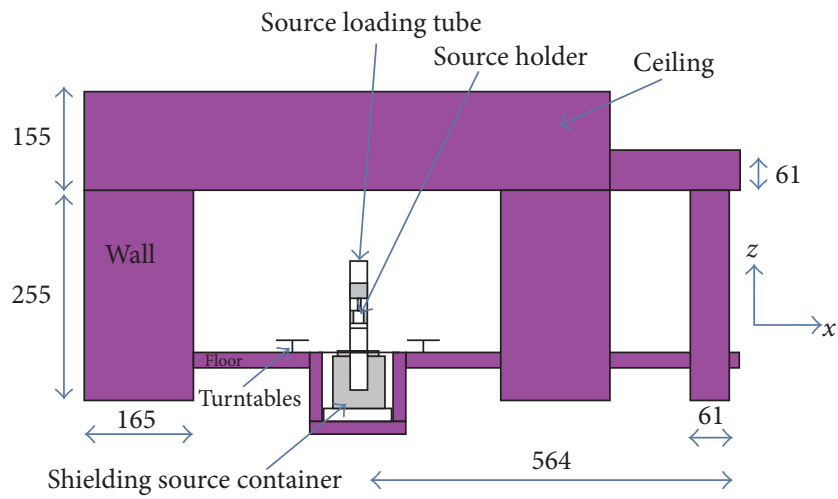

FIGURE 2: MCNPX model $X Z$ view of the Gamma Irradiation Laboratory.

took the values from 1 (source), 2, 4, 8, 16, 32, 64, and 128 to 256 (at point of interest). A value of 0 was assigned to the area outside of rectangular parallelepiped surface. Instead of the sphere as exclusion surface, rectangular parallelepiped surface is used to allow reducing the computation time. The points tallied along the passage of the labyrinth are illustrated in Figure 4.

The isodose curves in \% of the gamma dose rate distribution using MATLAB in the GB-127 source are presented in Figure 5.

It can be observed from this figure that sources rack consists of 24 holes with 12 double encapsulated radioactive cylindrical pencils, model C-198. The total initial activity of the sources was $2.127 \mathrm{TBq}(57.494 \mathrm{Ci}$ ) (18 August 2011).

Figure 6 shows the dose rate distribution for the tally points with and without the hole at the door obtained with MCNPX code.

The radiation doses detected at points 4 and 5 are the result of secondary gammas produced by Compton scattering and by production of pairs, which are scattered and transmitted in the lower left corner of the labyrinth. There is a rapid reduction between points 4 and 5 and although point 5 is closer to the primary source, fewer dispersion gammas arrive from the lower left corner. That makes the radiation in the corridor, where points 1, 2, 3, 4, and 5 are located, higher
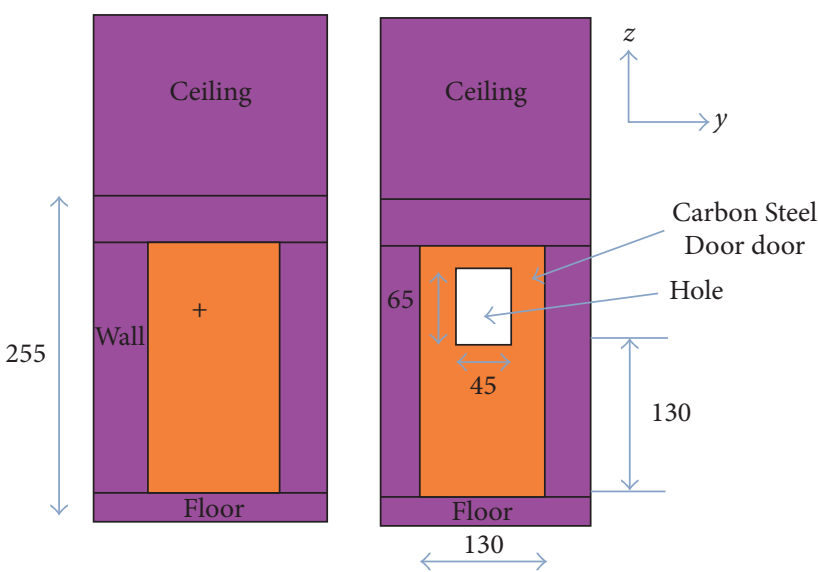

FIGURE 3: MCNPX model $Y Z$ view of the door with and without hole in the labyrinth entrance of the CDTN Gamma Irradiation Laboratory. All dimensions are given in $\mathrm{cm}$.

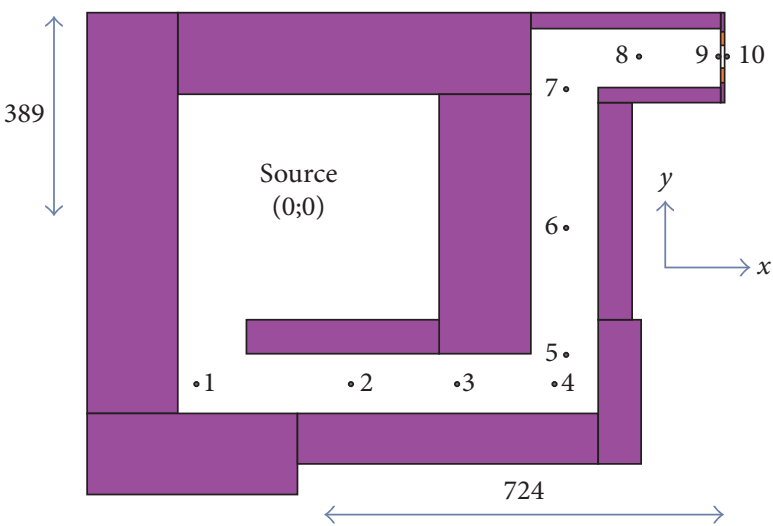

FIGURE 4: MCNPX model $X Y$ view of the Gamma Irradiation Laboratory with localizations of points tallied.

than that in the corridor with points 6 and 7 , and, in turn, the radiation here is much lower than that in the corridor where points 8 and 9 are located. There is a reduction between 5 and 6 , given that the scattered gammas do not reach the bottom wall even though that wall is closer to the primary source.

It is observed that the dose rates are decreasing considerably along the corridor in the direction of the labyrinth door, as expected. At position 1, the dose rate is very high, since this point receives the primary gamma radiation beam from the cobalt source. At the other positions, the incident radiation beam is originated from the secondary reflections or transmission on the shielding walls.

The knowledge of the doses inside the labyrinth (points 1 to 9) is relevant in terms of doses deposited in the product in order to be able to implement a protocol of irradiation for some products. These doses are not important in terms of radiation protection in the sense that no one can be in these zones. Only point 10 (outside the door) is important in terms of radiation protection.

From the simulated results, it was observed that dose rates at point 10 were not significantly changed when considering 

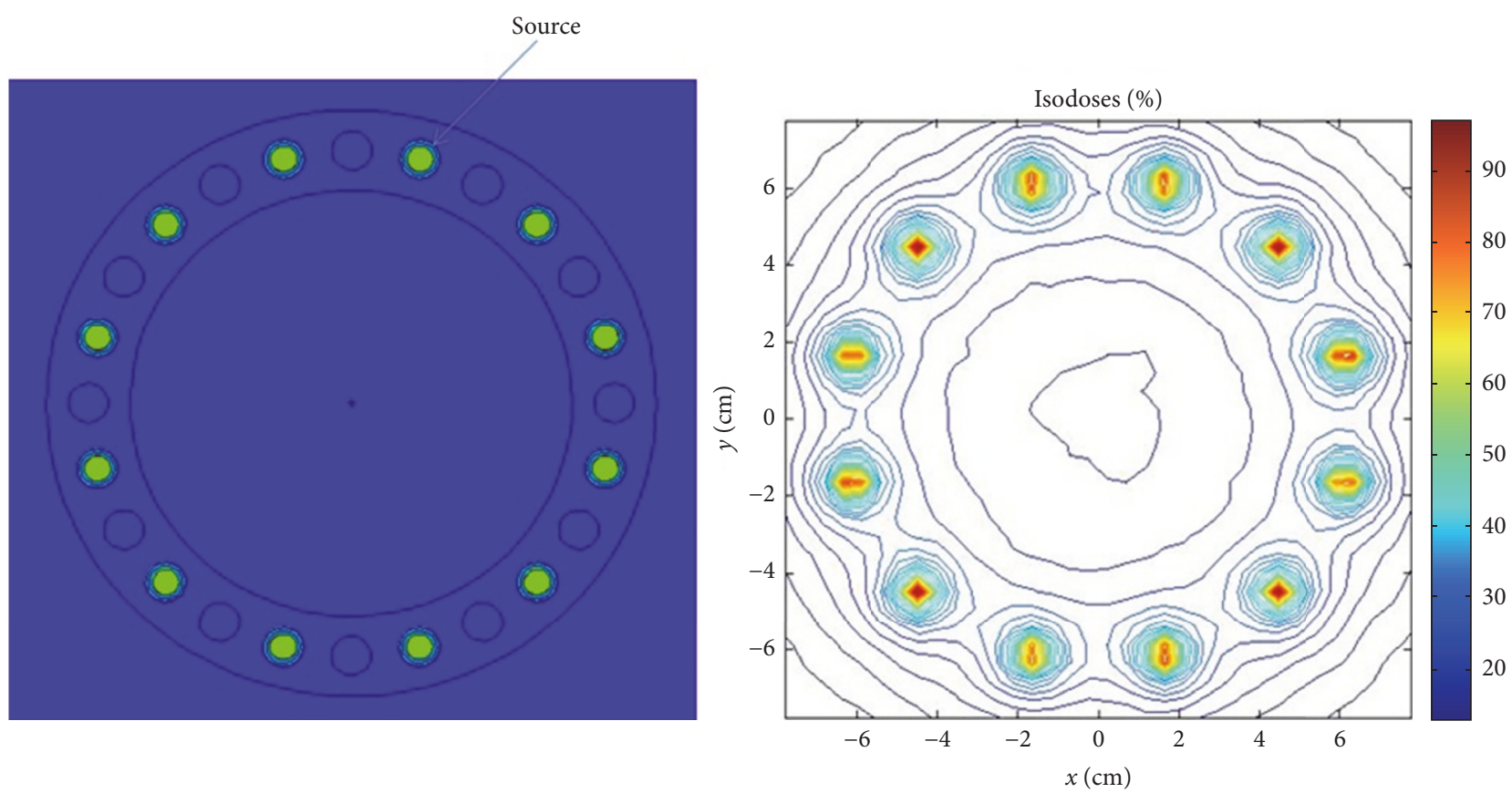

FIGURE 5: MCPX model and isodose curves in \% representation of XY view of the gamma dose rate distribution in the GB-127 source.

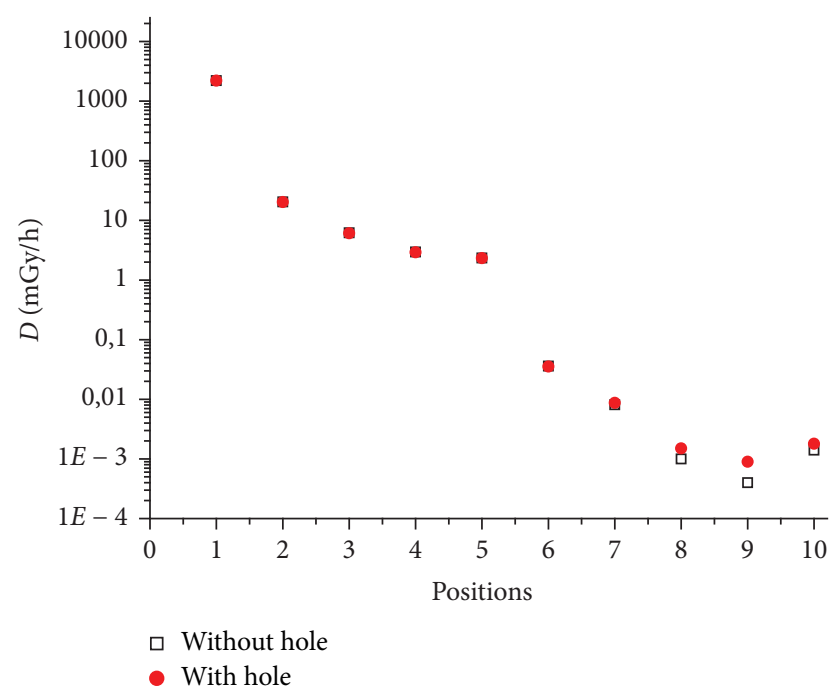

Figure 6: Dose rate distribution as function of positions of evaluated points obtained with MCNPX code with ${ }^{*}$ F5 tally.

the original project and the proposed modification with inclusion of the hole at the labyrinth door to allow the loading of irradiating products.

Table 1 summarizes the dose rate comparisons considering the original project of the labyrinth entrance door and the addition of the hole at the labyrinth entrance door. In the calculation with MCNPX ${ }^{*} \mathrm{~F} 5$ tally the relative error associated with the results was kept lower than $5 \%$ for all points of interest, requiring 100 million stories for the ${ }^{*} \mathrm{~F} 5$ tally. The computation time was 10 days.
TABLE 1: Comparison of dose rate without and with hole at the labyrinth entrance door obtained with MCNPX code with * F5 tally.

\begin{tabular}{lcc}
\hline Position & $\begin{array}{c}\text { Without hole } \\
\text { MCNPX D }(\mu \text { Sv } / \mathrm{h})\end{array}$ & $\begin{array}{c}\text { With hole } \\
\text { MCNPX D }(\mu \mathrm{Sv} / \mathrm{h})\end{array}$ \\
\hline 9 & 0.40 & 0.90 \\
10 & 1.40 & 1.80 \\
\hline
\end{tabular}

It is worth mentioning that even in this worst-case scenario (hole at the labyrinth entrance door) calculations show that at all point of interests evaluated the doses rates are well below the occupational limit of $3 \mu \mathrm{Sv} / \mathrm{h}$.

The dose rate at position 10 is slightly higher than that of position 9 (inside the door). The value was calculated by ${ }^{*}$ F5 tally but the point detector (F5 tally), known as variance reduction technique, is one of the partially deterministic variance reduction methods implemented in MCNPX. For each source particle and each collision event, a deterministic estimate is made of the fluence contribution at the detector point with no interaction. In reality, there is an interaction with the irradiator structure and the walls. Even so, values were below the occupational limit of $3 \mu \mathrm{Sv} / \mathrm{h}$. The use of F5 tally was a necessity because the analog random walk was inefficient with F6 tally. The MCNPX user is responsible for interpreting the results physically.

Therefore, even though the relative error with F5 tally was lower than 5\%, as mentioned earlier, this may be a false result, because the gamma dose rate outside the door (at position 10) ought to be lower than the dose rate inside the door (at position 9) by the gamma attenuation. 
TABLE 2: Comparison between measured and calculated gamma doses rates at position 10 .

\begin{tabular}{lccc}
\hline Position & $\begin{array}{c}\text { MCNPX } \\
\mathrm{D}(\mu \mathrm{Sv} / \mathrm{h})\end{array}$ & $\begin{array}{c}\text { Measured } \\
\mathrm{D}(\mu \mathrm{Sv} / \mathrm{h})\end{array}$ & $\begin{array}{c}\% \\
\text { difference }\end{array}$ \\
\hline 10 & 3.40 & 2.80 & 21 \\
\hline
\end{tabular}

In the future work the radiation buildup with the code MCNPX will be calculated and compared with the one obtained by conventional methods. It is necessary to make 2 calculations with the code MCNPX: one with all the structural materials of the system and another with only the primary beam of the source without the structural components of the system (labyrinth structures and walls). In the source definition, we will use a homogenized cylindrical model [20] to accelerate computation time for the panoramic gamma irradiator.

TLD dosimeters were used for validation of calculated gamma doses. In 2014, the sources rack consists of 24 holes with 16 double encapsulated radioactive cylindrical pencils and the source activity was $1,427 \mathrm{TBq}(38.585 \mathrm{Ci})$. Table 2 compares the values of the dose rates outside the door without the hole in 2014.

The simulations have overestimated experimental dose rate values with a difference of $21 \%$ and $1.9 \%$, compared with the experimental data. The gamma dose rate after the door will not exceed the limit established by the standards for OEIs in controlled area, namely, $3 \mu \mathrm{Sv} / \mathrm{h}$ [9].

\section{Validation of Simulated Model}

To validate the simulation, we have the doses rates measured by MDS Nordion-supplied Fricke dosimeters at a distance of $1 \mathrm{~m}$ from the source centre, near each of the turntables on 30 August 2002 [20]. In 2002, the sources rack consists of 24 holes with 16 double encapsulated radioactive cylindrical pencils and the source activity was $1,924 \mathrm{TBq}(52.021 \mathrm{Ci})$. The original configuration provided by the manufactures in 2002 was considered in the validation.

Table 3 compares the values of the doses rates at a distance of $1 \mathrm{~m}$ from the source centre for each position, obtained from simulation with those reported by MDS Nordion. The details of validation were presented in previous work [21].

As shown, error values lower than $9 \%$ were found between MCNPX and measurements values. It was concluded that the geometric simulation, the source definition, and the calculation procedure of doses rates were satisfactory.

A numerical model of the labyrinth of the gamma irradiator was implemented for the first time. In addition, any future changes in the geometry and the shielding of the facility can be calculated beforehand and optimized as well. This simulation could become an alternative to experimental dosimetry measurements.

\section{Conclusions}

The Monte Carlo code MCNP was used to verify the shielding at the labyrinth entrance door, even with the hole at the
TABLE 3: Comparison between the values of the doses rates at a distance of $1 \mathrm{~m}$ from the source centre for each position obtained from simulation and reference values.

\begin{tabular}{lccc}
\hline Position & $\begin{array}{c}\text { MDS Nordion-supplied } \\
\text { Fricke absorbed-dose } \\
\text { rate }(\mathrm{Gy} / \mathrm{h})\end{array}$ & $\begin{array}{c}\text { MCNPX } \\
\text { Absorbed-dose } \\
\text { rate }(\mathrm{Gy} / \mathrm{h})\end{array}$ & \% error \\
\hline 1 & 543.00 & 586.63 & -8.03 \\
2 & 556.00 & 589.61 & -6.04 \\
3 & 546.00 & 575.64 & -5.43 \\
4 & 556.00 & 573.40 & -3.13 \\
\hline
\end{tabular}

labyrinth entrance door opened (worst-case scenario). The obtained dose rate value is below the established dose limits by the national Brazilian regulations and the international recommendations for workers in controlled areas of $3 \mu \mathrm{Sv} / \mathrm{h}$. Therefore, the opening of a hole at the labyrinth door for the installation and operation of automated product loading system by the workers is secure from the point of view of dosimetry assessment.

\section{Conflicts of Interest}

The authors declare that they have no conflicts of interest.

\section{Acknowledgments}

This work was supported by the following Brazilian institutions: Nuclear Technology Development Centre (CDTN), Brazilian Nuclear Energy Commission (Cnen), Research Support Foundation of the State of Minas Gerais (Fapemig), Brazilian Council for Scientific and Technological Development (CNPq), and Coordination for the Improvement of Higher Education Personnel (Capes).

\section{References}

[1] G. A. Soares, P. Squair, F. C. L, L. C. Meira-Belo, and P. A. Grossi, "Blood compouns irradiation process: assessment of absorbed dose using fricke and thermoluminiscent dosimetric systems," in Proceedings of the International Nuclear Atlantic Conference (Inac), Brazilian Nuclear Energy Association, Rio de Janeiro, Brazil, 2009.

[2] A. S. Medeiros, M. R. Gual, C. Pereira, and L. O. Faria, "Thermal analysis for study of the gamma radiation effects in poly(vinylidene fluoride)," Radiation Physics and Chemistry, vol. 116, pp. 345-348, 2015.

[3] H. C. Silva and F. S. M, "Beryl colorless, quartz, and brazilianita study using $\mathrm{x}$-ray diffraction, spectroscopy in the infrared region and gamma irradiation in," in Proceedings of the Semana de Engenharia Nuclear e Ciências das Radiações (Sencir), Núcleo De Divulgação Científica, Belo Horizonte, Brazil, 2014, in Portuguese.

[4] G. S. M. B. de Souza, L. A. Rodrigues, W. J. de Oliveira et al., "Disinfection of domestic effluents by gamma radiation: Effects on the inactivation of Ascaris lumbricoides eggs," Water Research, vol. 45, no. 17, pp. 5523-5528, 2011.

[5] A. L. Oliveira et al., "Qualidade microbiologica da carne de frango irradiada em embalagem convencional e a vácuo," in 
Arquivo Brasileiro de Medicina Veterinária e Zootecnia, vol. 61, pp. 1210-1217, SciELO, São Paulo, SP, Brasil, 2009, http://dx.doi .org/10.1590/S0102-09352009000500026.

[6] E. H. M. Nunes, F. S. Lameiras, M. Houmard, and W. L. Vasconcelos, "Spectroscopic study of natural quartz samples," Radiation Physics and Chemistry, vol. 90, pp. 79-86, 2013.

[7] IAEA-International Atomic Energy Agency, Trends in Radiation Sterilization of Health Care Products, STI/PUB/1313, International Atomic Energy Agency, Vienna, Austria, 2008.

[8] L. C. D. Ladeira, Development of a system for automation control for short time irradiations in panoramic gamma irradiators with dry storage [Ph.D. thesis], Ciência e Tecnologia das Radiações, Minerais e Materiais, Belo Horizonte, Brazil, 2015 (Portuguese).

[9] International Commission on Radiological Protection, "Annals of the ICRP," The 2007 recommendations of the international commission on radiological protection, JAICRP, vol. 37, no. 2-4, pp. 1-332, 2007, ICRP-103.

[10] CNEN Comissão Nacional de Energia Nuclear, Basic Guidelines on Radiological Protection, CNEN-NN-3.01 Regulatory Position 3:01/004:2011, Dose Constraint, Occupational Reference Levels and Area Classification, Instituto de Pesquisas energéticas e Nucleares, Rio de Janeiro, Brazil, 2011.

[11] J. S. Hendricks et al., "MCNPX 2.6.0 EXTENSIONS," Tech. Rep. LA-UR-08-2216, Los Alamos National Laboratory, Los Alamos, NM, USA, 2008.

[12] International Atomic Energy Agency (IAEA), Gamma irradiators for radiation processing, IAEA-TECDOC-1386, International Atomic Energy Agency, Vienna, Austria.

[13] International Atomic Energy Agency (IAEA), Security of Radioactive Sources, IAEA-TECDOC-1387, International Atomic Energy Agency, Vienna, Austria, 2009.

[14] IAEA - International Atomic Energy Agency, Manual on Panoramic Gamma Irradiators (Categories II and IV), IAEAPRSM-8 (Rev. 1), IAEA, Vienna, Austria, 1996.

[15] Health Physics Society, Safe design and use of panoramic, wet source storage gamma irradiators (category IV) and dry source storage gamma irradiators (category II), American National Standard Institute -N43.10, New York, NY, USA, 2001.

[16] International Commission on Radiation Units and Measurements, "Tissue substitutes in radiation dosimetry and measurement," ICRU Report 44, 1989.

[17] F. H. Attix, Introduction to Radiological Physics and Radiation Dosimetry, Wiley-VCH Verlag GmbH, Weinheim, Germany, 1986.

[18] M. R. Gual, P. A. Grossi, C. A. Caballero, L. C. D. Ladeira, and F. S. Lameiras, "Preliminary MCNPX Modelling of the F127 Source Shipping Container for the Gb-127 Co-60 Irradiator Facility," Transactions of the American Nuclear Society, vol. 112, pp. 575-576, 2015.

[19] A. L. Schwarz, R. A. Schwarz, and L. L. Carter, "MCNPX/ MCNPX Visual editor computer code version 22S," February, 2008.

[20] Comissto Nacional de Energia Nuclear (CNEN). Dosimetry Report DR-IR-214, G127 Dry storage irradiator, CNEN, dosimetry Nordion, Brazil, 2002.

[21] M. R. Gual, F. M. Milian, A. Z. Mesquita, and C. Pereira, "New source models to represent the irradiation process in panoramic gamma irradiator," Applied Radiation and Isotopes, vol. 128, pp. 175-182, 2017. 


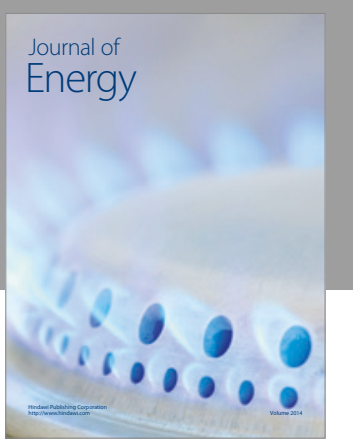

Journal of

Industrial Engineering
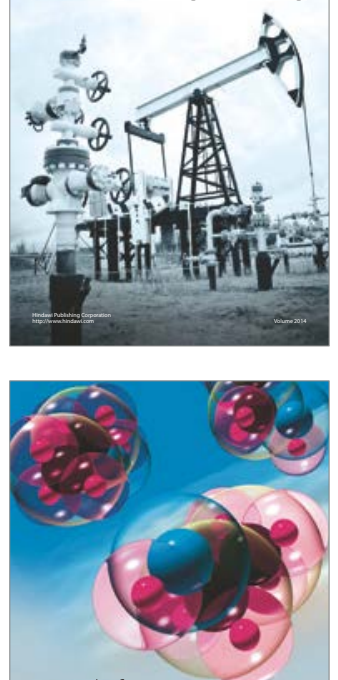

Fuels
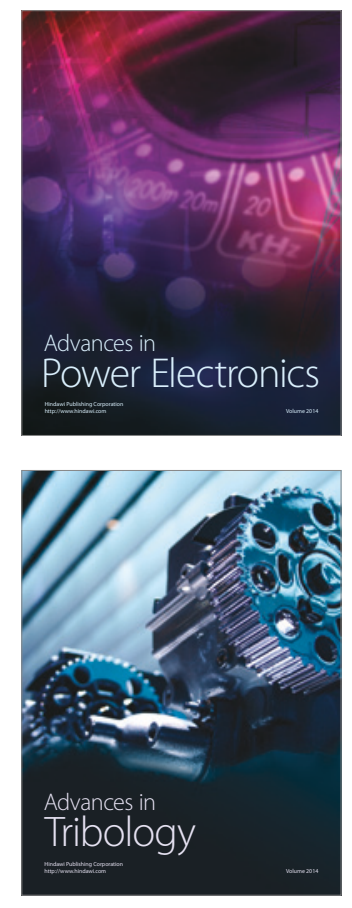
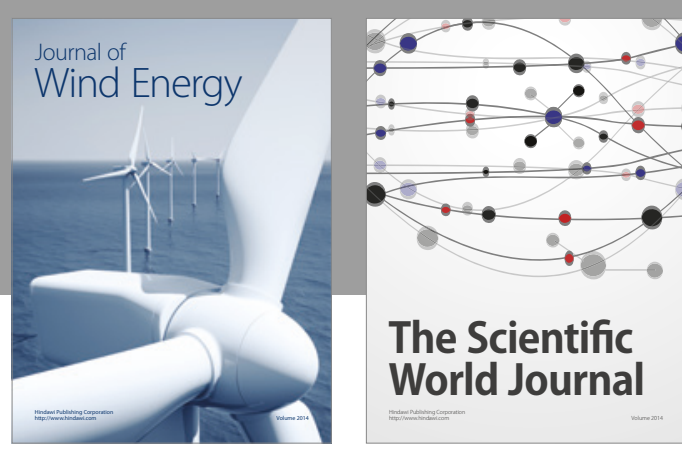

The Scientific World Journal
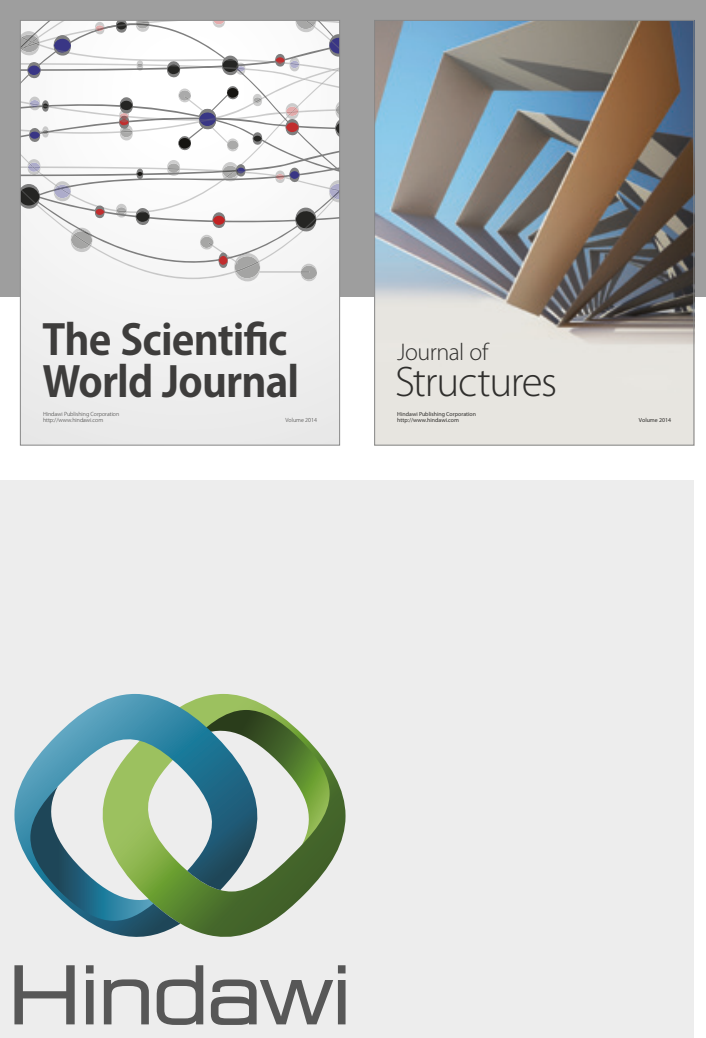

Submit your manuscripts at

https://www.hindawi.com
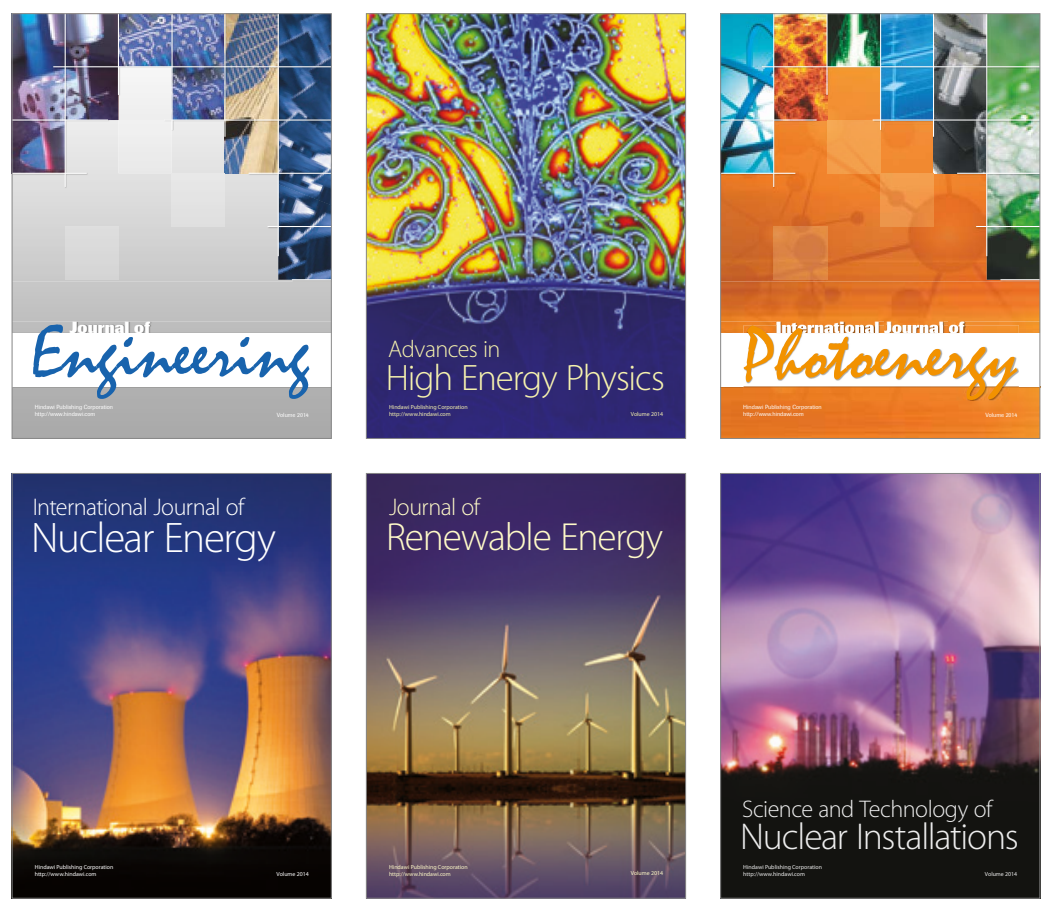

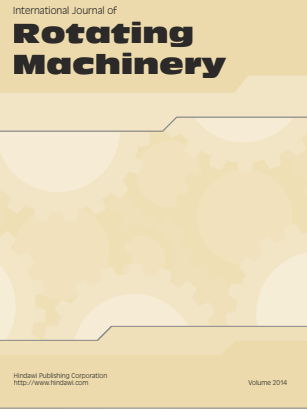

Journal of

Petroleum Engineering

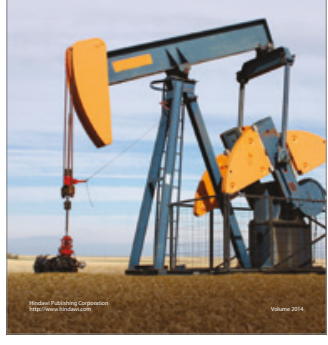

Journal of
Solar Energy
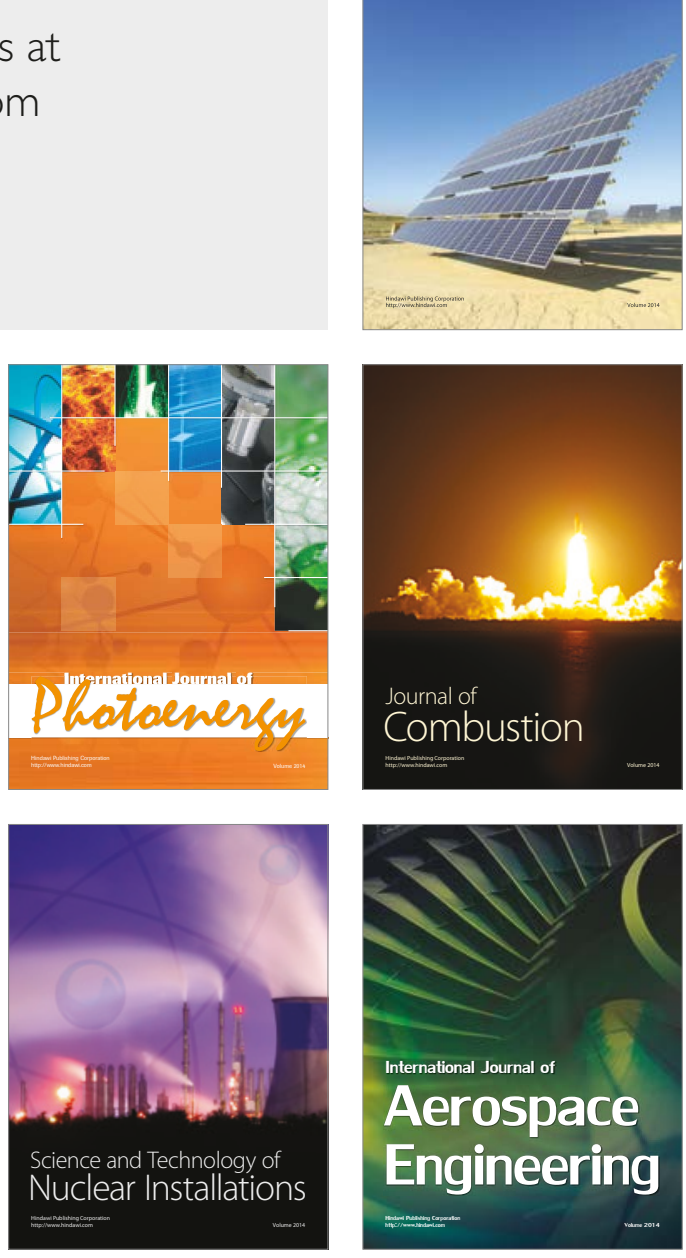